\title{
Groundbreaking gas source rock correlation research based on the application of a new experimental approach for adsorbed gas
}

\author{
SHI BaoGuang*, SHEN Ping, WANG XiaoFeng \& ZHEN JianJing \\ The Key Laboratory of Oil and Gas Resources, Institute of Geology and Geophysics, Chinese Academy of Sciences, Lanzhou 730000, China
}

Received July 16, 2012; accepted September 12, 2012; published online October 20, 2012

\begin{abstract}
Many years of experimentation have led to the development and improvement of equipment and methods used to make gas source rock correlations. By crushing samples using a ball mill and directly collecting adsorbed gases in the absence of aqueous media under high vacuum conditions, most possible interference factors, such as atmospheric pollution, crushing-induced pyrolysis, and gas collection by aqueous media are eliminated. This greatly enhances the volume percentage of hydrocarbon gas in the acquired adsorbed gases, with maxima up to more than $80 \%$. The actual measurement of carbon isotopic series can be carried out to such an extent as to be $\delta^{13} \mathrm{C}_{1}-\delta^{13} \mathrm{C}_{5}$. A preliminary study using newly established equipment and methods has indicated the following. (1) The carbon isotopic composition of ethane in adsorbed gases on hydrocarbon source rocks can be used to distinguish the types of source rocks. This is consistent with results obtained by using organic geochemical parameters for source rocks, and illustrates that it is highly feasible to use the carbon isotopic composition of ethane in natural gases as a parameter for distinguishing the types of source rocks. (2) The thermal evolution degree $\left(R_{\mathrm{o}}\right)$ of hydrocarbon-source rocks calculated in terms of the carbon isotopic composition of methane in adsorbed gases on hydrocarbon source rocks agrees well with the vitrinite reflectance actually measured in the source rocks. This confirms the reliability of the relationship between the carbon isotopic composition of methane in natural gases and the thermal evolution degree determined using statistics. (3) Finally, a direct gas source correlation method for natural gases has been established, and the expression of $\log R_{\mathrm{o}}$ vs. $\delta^{13} \mathrm{C}_{1}$ established in terms of actually measured $\delta^{13} \mathrm{C}_{1}$ values of methane in absorbed gases. $R_{\mathrm{O}}$ values of hydrocarbon source rocks have been established as well, thus creating favorable conditions for precise oil-and-gas source correlations in exploration areas.
\end{abstract}

adsorbed gas, gas source correlation, carbon isotopic composition, maturity

Citation: Shi B G, Shen P, Wang X F, et al. Groundbreaking gas source rock correlation research based on the application of a new experimental approach for adsorbed gas. Chin Sci Bull, 2012, 57: 4746-4752, doi: 10.1007/s11434-012-5504-5

Atoms or ions on the surface of rock pores have the ability to adsorb gases or liquid as a result of their surplus valence force field. As they diffuse and migrate, natural gases will be continuously adsorbed onto rocks [1-3]. A range of physical approaches can convert the adsorbed state of a natural gas to the free state, followed subsequently by gas collection. This process is referred to as gas adsorption in the field of oil and gas geochemistry [4]. Adsorbed gases are of great significance both in theory and in practice in constraining the genesis of natural gases, gas source correlation, oil and gas migration and accumulation, assessments of hydrocarbon source rocks and reservoir layers, as well as

*Corresponding author (email: sbg168@ hotmail.com) for such topical research fields as coal-measure gas, shale gas, or impact sandstone gas [3-15].

At present in China, domestically available adsorbed gas degasification-collection equipment [16-21] can be divided into two main categories. The first category consists of adsorbed gas degasification-collection systems that use water as the airtight medium, and the other category involves vacuum degasification-dewatering gas collection systems. Due to the presence of aqueous media, these two categories of equipment are low-vacuum, high-background and higheak rate systems. In addition, due to limiting factors such as the small size of the inlet sample or crushing sample and other pretreatments, the hydrocarbon gases in acquired adsorbed gases are low in amount and concentration. This 
results in a situation where the available experimental instruments make it difficult to precisely and reliably determine the hydrocarbon gas components in the adsorbed gases using conventional methods, especially isotopic composition data. Internationally, little has been reported on adsorbed gases, and no data concerning this subject is available to be referenced. This study, by taking advantage of many years of practice and exploration, has overcome the aforementioned disadvantages of the equipment and provided a basis for the establishment of more scientifically reliable equipment for adsorbed gas degasification and collection. The geochemical characteristics of carbon isotopes in adsorbed gases found on hydrocarbon-source rocks in the Ha-Tu, Santanghu and Liaohe basins have confirmed, for the first time, that that there is an excellent affinity between adsorbed gases and corresponding hydrocarbon-source rocks. As a result, a new method has been established for direct gas source correlation and hydrocarbon source rock assessment.

\section{Experimental set up}

The newly established adsorbed gas degasification-collection device presented in this paper is the culmination of many years of modifications and testing based on a prototype six-jar planetary high-energy ball mill made by the Fritsch Company of Germany. The experiments follow the following steps. (1) The 100-200 g rock samples and a fixed number of stainless steel balls are put into a vacuum canister, then the vacuum canister is sealed and evacuated by a vacuum pump to between $10^{-4}$ and $10^{-5}$ of standard atmospheric pressure. (2) The vacuum canister ball mill assembly is connected to a power supply and spun at high speed. During this process, the rock samples in the vacuum canister are crushed by the stainless steel balls and their absorbed gases are desorbed under the high vacuum. (3) The ball mill runs for 3-5 min then is powered down. The 0.5 to $1.0 \mathrm{~mL}$ of absorbed gas in the vacuum canister is acquired by gas- collection equipment. The carbon component and carbon isotopic composition are then measured.

Compared to devices developed by previous researchers, this new device has several advantages. (1) The degasification device has the ability to test a large sample (100-200 g). As a result, a greater amount of adsorbed gas can be acquired. (2) The degasification device is capable of maintaining a high vacuum, varying between $10^{-4}$ and $10^{-5}$ of standard atmospheric pressure. Because of the high vacuum, low atmosphere background and low penetration, the acquired adsorbed gases are therefore generally free from atmospheric pollution. (3) The degasification device runs for a relatively short time duration for crushing under lowtemperature vacuum conditions. The duration of sample crushing under vacuum is about 3-5 $\mathrm{min}$ at a temperature between 40 and $50{ }^{\circ} \mathrm{C}$. Therefore, the acquired adsorbed gases are not affected by "pyrolysis gas". (4) The use of a water-free gas collection device to collect adsorbed gases avoids the interruption of the components and isotopic composition of adsorbed gases that occurs with dewatering gas-collection methods. Measurement and analysis indicated that the acquired adsorbed gases are composed mainly of hydrocarbons and carbon dioxide, with the hydrocarbon gas accounting for more than $80 \%$. This suggests that the gas was derived from hydrocarbon source rocks then preserved in an adsorbed state in the source rocks after migration. The acquired adsorbed gas samples all can be measured reliably for their $\delta^{13} \mathrm{C}_{1}-\delta^{13} \mathrm{C}_{3}$ data, and some of them can even be measured for $\delta^{13} \mathrm{C}_{4}-\delta^{13} \mathrm{C}_{5}$. The $\delta^{13} \mathrm{C}$ values of adsorbed gas measured in parallel samples are reproducible with a deviation less than $0.3 \%$. This is an acceptable level for geochemical studies applied to adsorbed gases.

In this study, Shuixigou Group $\left(\mathrm{J}_{1-2} s h\right)$ mudstone and coalstone samples were selected from the Tu-Ha and Santanghu basins, as well as mudstone, oil shale and drilling core samples from the third $\left(\mathrm{Es}_{3}\right)$ and fourth $\left(\mathrm{Es}_{4}\right)$ members of the Shahejie Formation from the Liaohe Basin. Extraction experiments were undertaken for adsorbed gases using the degasification and gas collection method described above. The adsorbed gases were then measured for their carbon isotopic composition. Carbon isotopic analysis was undertaken at the Key Laboratory of Oil and Gas Resources, Chinese Academy of Sciences using GC-C/TC-IRMS techniques. An HP6890 model gas chromatograph and a DEL$\mathrm{TA}^{\text {plus }} \mathrm{XP}$ model isotopic mass spectrometer were employed in this study. The latter device has an analytical precision of $0.3 \%$ o for carbon isotopic composition. The results of the experimental analyses are listed in Table 1.

\section{Results and discussion}

\subsection{Types of organic matter in hydrocarbon source rocks}

At present, the results of adsorbed gas studies are mainly used for gas source correlations, which enable the investigation of a series of relevant scientific problems in petroleum geology. Gas source correlations are important for characterizing the type of organic matter in source rocks. This study used direct measurements of the carbon isotopic composition of adsorbed gases on source rock samples to distinguish the types of source rocks.

Table 2 lists basic data from the source rock samples in addition to some geochemical parameters that can be used to distinguish the types of organic matter present. In accordance with the standards for geochemically assessing terrestrial hydrocarbon source rocks (the industrial standard for China's petroleum and natural gases SY/T 5735-1995), pyrolysis coefficients were determined. Additionally, the micro-component contents of four samples (Zhang 1, Wa 17, Ou 24, Da 15) were used in the classification. Note that 
Table 1 Measured carbon isotope data for the adsorbed gases on source rocks

\begin{tabular}{lllllllc}
\hline \multicolumn{1}{c}{ Basin } & Sample No. & Depth $(\mathrm{m})$ & Strat. & Litho. & $\delta^{13} \mathrm{C}_{1}(\mathrm{PDB}, \%)$ & $\delta^{13} \mathrm{C}_{2}(\mathrm{PDB}, \% o)$ & $\delta^{13} \mathrm{C}_{3}(\mathrm{PDB}, \% o)$ \\
\hline & Dabu 2-1 & 3655.73 & $\mathrm{~J}_{2} x$ & mudstone & -38.9 & -22.9 & - \\
& Dabu 2-2 & 3655.76 & $\mathrm{~J}_{2} x$ & mudstone & -41.2 & -28.9 & -23.6 \\
& Dabu 2-3 & 3658.44 & $\mathrm{~J}_{2} x$ & mudstone & -41.6 & -26.7 & - \\
Tu-Ha, & Lingshen 1-1 & 3846.24 & $\mathrm{~J}_{2} x$ & coalstone & -38 & -21 & -26.7 \\
Santanghu & Lingshen 1-2 & 3940 & $\mathrm{~J}_{2} x$ & coalstone & -45.3 & -17.6 & -19.7 \\
basins & Lingshen 1-3 & 4046.5 & $\mathrm{~J}_{1} s$ & mudstone & -43.5 & -27.7 & -27.3 \\
& Lingshen 1-4 & 4079.7 & $\mathrm{~J}_{1} s$ & mudstone & -43.5 & -27.9 & -25.5 \\
& Lingshen 1-5 & 4080.25 & $\mathrm{~J}_{1} s$ & mudstone & -39.6 & -29.2 & -27.7 \\
& Du 1 & 3297 & $\mathrm{~J}_{2} x$ & mudstone & -46 & -24.9 & - \\
& Lian 4 & 4181.5 & $\mathrm{~J}_{1} b$ & mudstone & -30.1 & -29.3 & - \\
\hline \multirow{5}{*}{ Liaohe Basin } & Da15 & 4216.9 & $\mathrm{Es}_{3}$ & mudstone & -40.7 & -27.2 & -23.9 \\
& Ou 24 & 2361 & $\mathrm{Es}_{3}$ & mudstone & -48.2 & -25.9 & -25.8 \\
& Wa 17 & 3472 & $\mathrm{Es}_{3}$ & mudstone & -49.8 & -31.4 & -26.5 \\
& Zhang 1 & 1786.23 & $\mathrm{Es}_{4}$ & shale & -49.7 & -31.2 & -32.5 \\
\hline
\end{tabular}

Table 2 Classification data for organic material in source rocks

\begin{tabular}{|c|c|c|c|c|c|c|}
\hline Sample No. & $\mathrm{IH}(\mathrm{mg} / \mathrm{g})$ & $\mathrm{S}_{1}+\mathrm{S}_{2}(\mathrm{mg} / \mathrm{g})$ & $\mathrm{S}_{2} / \mathrm{S}_{3}$ & $D(\%)$ & Pyrolytic classification & Microscopic classification \\
\hline Dabu 2-1 & 8 & 0.09 & 0.17 & 2.02 & III & - \\
\hline Dabu 2-2 & 6 & 0.08 & 0.1 & 4.15 & III & - \\
\hline Dabu 2-3 & 9 & 0.08 & 0.4 & 1.58 & III & - \\
\hline Lingshen 1-1 & 157 & 124.48 & 15.32 & 14.47 & $\mathrm{II}_{2}$ & - \\
\hline Lingshen 1-2 & 181 & 133.18 & 10.52 & 16.76 & $\mathrm{II}_{2}$ & - \\
\hline Lingshen 1-3 & 22 & 0.12 & 0.26 & 4.53 & III & - \\
\hline Lingshen 1-4 & 301 & 3.71 & 17.8 & 26.1 & $\mathrm{II}_{2}$ & - \\
\hline Lingshen 1-5 & 122 & 1.62 & 16.22 & 11.3 & $\mathrm{II}_{2}, \mathrm{III}$ & - \\
\hline Du1 & 172 & 13.75 & 5.07 & 14.69 & $\mathrm{II}_{2}$ & - \\
\hline Lian 4 & 253 & 7.2 & 57.75 & 21.89 & $\mathrm{II}_{1}, \mathrm{II}_{2}$ & - \\
\hline Da15 & 47 & 0.55 & 0.7 & 6.17 & III & III \\
\hline Ou 24 & 249 & 75 & 5.32 & 21.17 & $\mathrm{II}_{2}$ & III \\
\hline Wa 17 & 328 & 7.21 & 20.74 & 30.53 & $\mathrm{I}, \mathrm{II}_{1}$ & I \\
\hline Zhang 1 & 676 & 60.09 & 109.04 & 57.33 & $\mathrm{I}, \mathrm{II}_{1}$ & $\mathrm{II}_{1}$ \\
\hline
\end{tabular}

there is more consistency in the pyrolysis classification results and those of microscopic examination classification.

The $\delta^{13} \mathrm{C}_{2}$ value is an important indicator for distinguishing types of natural gases. The samples used in this study were collected from low-maturity organic source rocks, so a $\delta^{13} \mathrm{C}_{2}$ value of $-29 \%$ was taken as a boundary value to separate oil-type from coal-type adsorbed gases [22]. The types of organic matter identified in source rocks from the $\delta^{13} \mathrm{C}_{2}$ values of adsorbed gases are consistent with those determined from organic geochemistry data obtained from source rock samples (Figure 1). In other words, oil-type gases were derived from sapropelic and humus-sapropelic hydrocarbon source rocks, whereas coal-type gases were derived from humus and sapropelic-humus hydrocarbon source rocks. The four gas samples in Figure 1 all fall within the field of oil-type gases. As for these four gas samples, the $\delta^{13} \mathrm{C}_{2}$ values of adsorbed gases from Wa 17 and Zhang 1 are less than $-31 \%$, and the adsorbed gases have obvious characteristics of oil-type gases. These samples are the only two (of 14) that are designated as type $\mathrm{I}$ or type $\mathrm{II}_{1}$ in accordance with two kinds of measured organic geochemical parameters. The other two samples falling within the field of oil-type gases were collected from Lingshen 1 and Lian 4. Their source rock organic matter was classified as humus type in terms of pyrolysis experimental data (Table 2), but the $\delta^{13} \mathrm{C}_{2}$ values of these two adsorbed gases are $-29.2 \%$ o and $-29.3 \%$, respectively, which fall within the field for oil-type gases. In combination with the fact that the analytical error of the $\delta^{13} \mathrm{C}$ value is $\pm 0.3 \%$, and consistent with the analysis of their geological data, the organic matter can reasonably be classified as humus type.

It therefore can be concluded that source rock types can be directly distinguished in terms of the $\delta^{13} \mathrm{C}_{2}$ values of adsorbed gases acquired by the newly developed degasification 


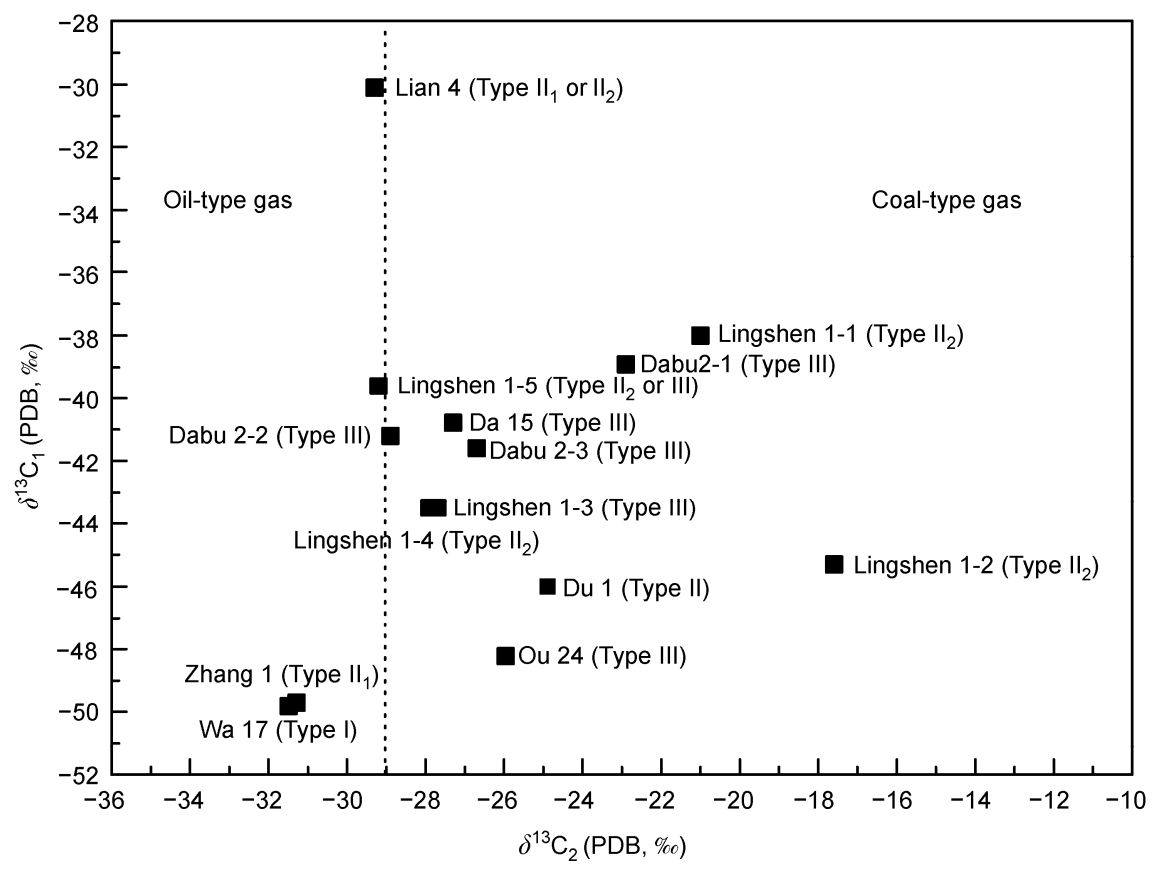

Figure 1 Schematic diagram of source rock/natural gas classification in terms of the $\delta^{13} \mathrm{C}_{1}$ and $\delta^{13} \mathrm{C}_{2}$ values of adsorbed gases.

gas collection device. This also indicates that there is a good "affinity" between absorbed gases and their source rocks, thereby providing a new approach for distinguishing the types of source rocks.

\subsection{Maturity of hydrocarbon source rocks}

In the geochemical study of natural gases, the maturity of natural gas source rocks generally is calculated in agreement with $\delta^{13} \mathrm{C}_{1}$ values as

$$
\delta^{13} \mathrm{C}_{1}(\%)=a \lg R_{\mathrm{o}}+b
$$

where $a$ and $b$ are constants. This has been established in accordance with abundant carbon isotope data for natural gases combined with source rock maturity data for the study area. In past studies, this empirical model generally was confirmed to be desirable, but little has been reported about the regression of $\log R_{\mathrm{o}}$ vs. $\delta^{13} \mathrm{C}_{1}$ in accordance with measured maturities $\left(R_{\mathrm{o}}\right)$ of source rocks and the $\delta^{13} \mathrm{C}_{1}$ values of adsorbed gases on the source rocks.

Table 3 lists the measured $R_{\mathrm{o}}$ values, the $\delta^{13} \mathrm{C}_{1}$ values of adsorbed gases of source rock samples, and the $R_{\mathrm{o}}$ values calculated with the expression

$$
\delta^{13} \mathrm{C}_{1}(\% \circ)=48.77 \lg R_{\mathrm{o}}-34.1
$$

at an early stage in the evolution of coal-type gases [23]. The results show that the measured $R_{\mathrm{o}}$ values of the source rocks are consistent with those calculated in terms of the $\delta^{13} \mathrm{C}_{1}$ values of adsorbed gases on source rocks.

A correlation diagram of the measured and calculated $R_{\mathrm{o}}$ values of humus source rocks (Figure 2) is drawn in terms of the data from Table 3 . In this figure, the $R_{\mathrm{o}}$ values of
Table 3 The $\delta^{13} \mathrm{C}_{1}$ values of adsorbed gases and their measured and calculated $R_{\mathrm{o}}$ values

\begin{tabular}{lccc}
\hline Sample No. & $\delta^{13} \mathrm{C}_{1}(\mathrm{PDB}, \%)$ & Measured $R_{\mathrm{o}}(\%)$ & Calculated $R_{\mathrm{o}}(\%)$ \\
\hline Dabu 2-1 & -38.9 & 0.73 & 0.8 \\
Dabu 2-2 & -41.2 & 0.66 & 0.72 \\
Dabu 2-3 & -41.6 & 0.73 & 0.7 \\
Lingshen 1-1 & -38 & 0.82 & 0.83 \\
Lingshen 1-2 & -45.3 & 0.66 & 0.59 \\
Lingshen 1-3 & -43.5 & 0.55 & 0.64 \\
Lingshen 1-4 & -43.5 & 0.53 & 0.64 \\
Lingshen 1-5 & -39.6 & 0.76 & 0.77 \\
Du 1 & -46 & 0.46 & 0.57 \\
Lian 4 & -30.1 & 1.1 & 1.21 \\
Da 15 & -40.7 & 0.96 & 0.73 \\
Ou 24 & -48.2 & 0.53 & 0.51 \\
Wa 17 & -49.8 & 0.41 & 0.36 \\
Zhang 1 & -49.7 & 0.35 & 0.37 \\
\hline
\end{tabular}

source rocks from Wa 17 and Zhang 1 are not listed because they are dominated by sapropelic source rocks. As can be seen from Figure 2, there is a good linear relationship (correlation coefficient $r=0.84$ ) between the measured and calculated $R_{\mathrm{O}}$ values. This indicates that it is feasible to use the measured $R_{\mathrm{o}}$ values of source rocks in the study area and the $\delta^{13} \mathrm{C}_{1}$ values of adsorbed gases on the corresponding source rocks, to directly establish the expression $\log R_{\mathrm{o}}$ vs. $\delta^{13} \mathrm{C}_{1}$ for the study area. Although no progress had been made on the above petroleum geology problem in recent years, the sophistication and perfection of the relevant techniques and methods presented here provide a new solution. 


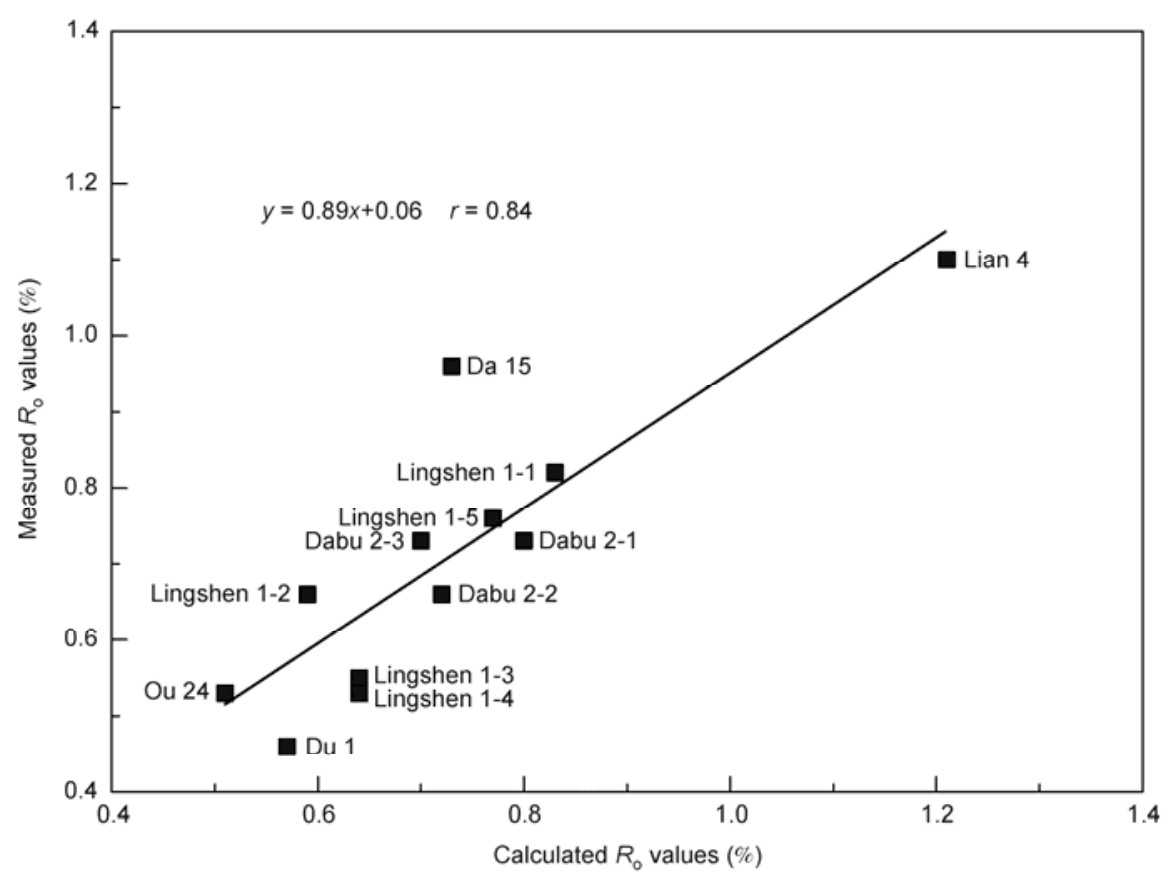

Figure 2 Correlation diagram for measured and calculated values $\left(R_{0}\right)$ for humus source rocks.

Based on available data, this study undertook a regression of measured $R_{\mathrm{o}}$ values for humus source rocks, then measured $\delta^{13} \mathrm{C}_{1}$ values of adsorbed gases on the corresponding source rocks, and presented the expression:

$$
\delta^{13} \mathrm{C}_{1}(\% o)=35.37 \lg R_{\mathrm{o}}-35.6,
$$

with $r=0.83$. Among the measured $R_{\mathrm{o}}$ values, the $R_{\mathrm{o}}$ value of the source rock samples collected from Lian 4 is $1.1 \%$, the only one $>1 \%$. In consideration of the fact that the $R_{\mathrm{o}}$ value at the intersection of the two-stage model of coal-type gases is about $1 \%$, the consideration of data from Lian 4 is justified. The above expression is appropriate for the early stage of evolution of humus source rocks.

In Figure 3, the above expression and the expression for the early stage of evolution of humus source rocks [23] are observed to be comparable. As a matter of fact, this expression in another form is shown in Figure 2, where it is much closer to the expression commonly used in research.

By applying the above analysis methods (i.e. employing the available adsorbed gas degasification-gas collection device and method) to some examples, this study is shown to be of pioneering significance and applicability in accurate oil and gas source correlations. Empirical deductions on the basis of statistics are no longer necessary in cases where the maturity $\left(R_{0}\right)$ of source rocks is determined in accordance with the $\delta^{13} \mathrm{C}_{1}$ values of natural gases. The $\delta^{13} \mathrm{C}_{1}$ values of adsorbed gases on source rocks in the working area and the $R_{\mathrm{o}}$ values of source rocks can be directly measured and verified, so as to invoke accurate oil and gas source correlations in the study area. This provides valuable scientific information on a great number of problems involved in petroleum geology, e.g., the genetic types of oils and gases, oil and gas migration and reservoir accumulation, accurate identification of regional hydrocarbon-source rocks, the within-the-region oil and gas potential and the orientation of oil and gas exploration.

This research has been carried out in conjunction with an immature gas subject. All of source rock samples were collected from Mesozoic to Cenozoic stratigraphy and remain in their original states because they only experience a relatively simple geological evolution through continued subsidence. Hence, the $\delta^{13} \mathrm{C}$ values of adsorbed gases can be used to accurately distinguish types of organic matter and maturity of relevant source rocks, and establish the equation of $\log R_{\mathrm{o}}$ vs. $\delta^{13} \mathrm{C}_{1}$. The key to realizing the above goal lies in the accuracy and reliability of the technology and methods used to characterize the adsorbed gases. To advance this research, further investigations are needed of source rock adsorbed gases from sedimentary basins that have experienced millions of years of geological evolution and complex multi-stage tectonic histories.

\section{Concluding remarks}

Through many years of investigations, the authors have designed and established the aqueous-media-free, highvacuum, ball-grinding adsorbed-gas degasification collection device and accompanying experimental method presented in this paper. This approach has a series of advantages (e.g. the large sample inlet, the high vacuum, the short time scale for sample crushing, the low crushing temperature and the collection of water and free gas) that cannot be matched by any previous design. In addition, the 


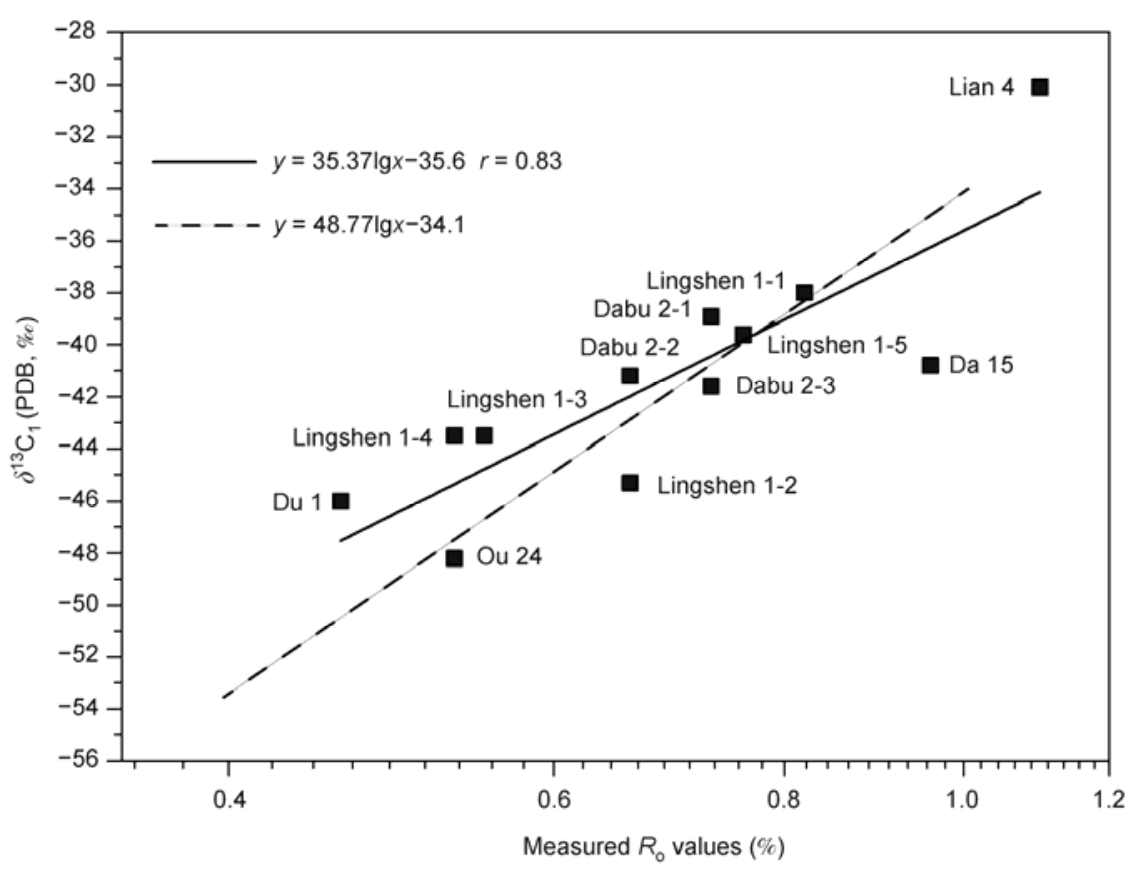

Figure $3 R_{\mathrm{o}}$ vs. $\delta^{13} \mathrm{C}_{1}$ correlation plot of humus source rocks.

hydrocarbon gas content in adsorbed gases is relatively high, which means that $\delta^{13} \mathrm{C}_{1}-\delta^{13} \mathrm{C}_{5}$ data can be collected. Studies involving the measurement of $\delta^{13} \mathrm{C}$ series data for adsorbed gases from hydrocarbon source rock samples collected from the Tu-Ha, Santanghu and Liaohe basins enable the following conclusions to be drawn.

Adsorbed gases can be divided into oil-type and gas-type gases in terms of their $\delta^{13} \mathrm{C}_{2}$ values. That is to say, the organic matter in their source rocks is dominated by sapropelic and humus types. This determination is fully consistent with the types of organic matter characterized by the measured organic geochemical parameters for the corresponding source rocks. This illustrates that it is feasible to use the carbon isotopic composition of ethane in natural gases as a parameter for determining the types of parent materials.

Based on the $\delta^{13} \mathrm{C}_{1}$ values of adsorbed gases, the maturities of source rocks were predicted, i.e., the $\delta^{13} \mathrm{C}_{1}$ values of adsorbed gases and the maturities $\left(R_{\mathrm{o}}\right)$ of the corresponding source rocks were calculated using the relationship $\log R_{\mathrm{o}}$ vs. $\delta^{13} \mathrm{C}_{1}$. Then the maturities $\left(R_{\mathrm{o}}\right)$ of the corresponding source rocks were compared with the measured $R_{\mathrm{o}}$ values of the studied source rocks. The results show that there is a clear linear relationship between calculated and measured $R_{\mathrm{o}}$ values, with the correlation coefficient reaching 0.84 . All this has proved the reliability of determining the relationship between the carbon isotopic composition of methane in natural gases using the statistical method and the thermal evolution degree.

Of the samples used in this study, 12 were collected from humus hydrocarbon source rocks. A regression of the correlations between $\delta^{13} \mathrm{C}_{1}$ data for adsorbed gases on the source rocks and the measured $R_{\mathrm{o}}$ values results in eq. (3), with $r=0.83$. This regression expression was established using, for the first time, (1) the measured $\delta^{13} \mathrm{C}_{1}$ values of adsorbed gases on natural source rock samples from an exploration area and (2) the measured $R_{\mathrm{o}}$ values from the same source rocks. In the past, this expression was statistically obtained with the help of abundant actual data. Such determinations have great significance for a wide range of geological investigations.

A tenuous oil-and-gas source correlation model now can be established for a given working area using the newly established experimental device and accompanying method. Further experimental approaches, based on this research, need to be developed to carry out more extensive investigations of some key issues concerning oil and gas geology. Such work should provide significant information, for example, on the genetic types of petroleum, oil and gas migration and accumulation mechanisms, accurate identification of regional hydrocarbon source rocks, regional oil and gas potential, and even the orientation of oil and gas exploration efforts.

This work was supported by the National Natural Science Foundation of China (41102090), the National Basic Research Program of China (2012CB214801), and the National Oil-Gas Importance Project of China (2011ZX05005-001). We gratefully thank Prof. Li Liwu and Associate Prof. Li Zhongping at the Key Laboratory of Oil and Gas Resources, Institute of Geology and Geophysics, Chinese Academy of Sciences for their help with the experimental technology.

1 Li G Z, Wang L Z. The desorption, analysis and application of adsorbed light hydrocarbon (in Chinese). Geophys Geochem Explor, 2000, 24: 34-42

2 Cheng T J, Li G Z, Chen Y J. New extraction technique of adsorption 
hydrocarbon gas and its role in surface oil and gas geochemical exploration (in Chinese). Pet Geol Exp, 2007, 29: 116-119

3 Cheng $\mathrm{T}$ J. New hydrocarbon detection technique based on conventional concept of adsorbed hydrocarbon (in Chinese). Geophys Geochem Explor, 2008, 32: 456-460

4 Xu Y C, Zhang X B, Shen P, et al. A breakthrough of researching reservoir adsorption gas and its significance. Chin Sci Bull, 1999, 44: 761-763

5 Zhang T W, Wang X B, Chen J F, et al. Carbon isotope composition of acidolysis hydrocarbons and its application to gas-source correlation in ordos basin, China. Chin Sci Bull, 1996, 41: 754-758

6 Zhang T W, Wang X B, Chen J F, et al. Chemical composition of gases as a geochemical tracer of natural gas migration (in Chinese). Acta Sedimentol Sin, 1999, 17: 627-631

7 Zhang X B, Xu Y C, Shen P, et al. Research summary and prospectsof hydrocarbon gases preservedin different states in china (in Chinese). Adv Earth Sci, 1997, 12: 230-235

8 Li G Z, Chen Y H. Logging technology of geophysically absorbed light hydrocarbons and its petroleum geological significance (in Chinese). Pet Explor Dev, 1999, 26: 96-102

9 Li G Z. Formation and characteristics of light hydrocarbon geochemical fields (in Chinese). Pet Nat Gas Geol, 1999, 20: 66-69

$10 \mathrm{Li} \mathrm{G} \mathrm{Z,} \mathrm{Yuan} \mathrm{Z} \mathrm{Y,} \mathrm{Hu} \mathrm{B,} \mathrm{et} \mathrm{al.} \mathrm{Identify} \mathrm{the} \mathrm{attribute} \mathrm{of} \mathrm{the} \mathrm{condensa-}$ ble gas or oil beds by using the analysis technology of headspace gas (in Chinese). Nat Gas Geosci, 2006, 17: 309-312

11 Li G Z, Cheng T J, Tang Y P, et al. The petroleum geological significance of phsically-absobed gas (in Chinese). Pet Geol Exp, 2006, 28: 484-488

12 Li G Z, Yuan Z Y, Hu B. Application of headspace gas technology to geochemical exploration (in Chinese). Chin Pet Explor, 2007, 6:
$47-51$

13 Li G Z, Hu B, Deng T L, et al. Analytic techniques and petroleum geological significance of different existing states of light hydrocarbons (in Chinese). Nat Gas Geosci, 2007, 18: 111-116

14 Zhao K B, Sun C Q. Application of hydrocarbon geochemical exploration technique in natural gas exploration (in Chinese). Pet Geol Experiment, 2004, 26: 574-584

15 Zhang Q, Jiang Q G, Tao C, et al. Degasification methods and application of high quality marine source rocks in South China (in Chinese). Petrol Geol Exp, 2008, 30: 527-531

16 Tong Q G, Jiang J G. The analysis method of adsorbed gases on rocks (in Chinese). Pet Geol Exp, 1984, 6: 76-77

17 Jiang M X, Chen W J. The analysis method of adsorbed gases on rocks (in Chinese). Pet Geol Exp, 1986, 8: 199-204

18 Zhang Y G. Generation, Accumulation and Preservation of Natural Gases (in Chinese). Nanjing: Hehai University Press, 1991. 55-65

19 Liu J Z, Xiang T S. Collection, quantitative analysis and carbon isotopic analysis methods of minor/trace hydrocarbon gases (in Chinese). Pet Geol Exp, 2003, 25: 492-497

20 Li L W, Zhang M J, Du L, et al. A heated extracting device for analyzing carbon and hydrogen isotopes in rock (in Chinese). Rock Miner Anal, 2005, 24: 135-137

21 Li J K, Liu W, Song L B, et al. New method of investigating the mixing proportion of natural gas and its application (in Chinese). Nat Gas Ind, 2005, 25: 14-16

22 Wang X F, Xu Y C, Shen P, et al. Geochemical characteristics and identification indexes of low-mature gases (in Chinese). Nat Gas Geosci, 2010, 21: 1-6

23 Liu W H, Xu Y C. A two stage model of carbon isotopic fractionation in coal gas (in Chinese). Geochimica, 1999, 28: 359-365

Open Access This article is distributed under the terms of the Creative Commons Attribution License which permits any use, distribution, and reproduction in any medium, provided the original author(s) and source are credited. 